\title{
Reading Development, Dyslexia and Phonological Skills.
}

Nick Ellis

Department of Psychology,

University College of North Wales,

Bangor,

Gwynedd.

LL57 2DG. 


\section{ABSTRACT}

This paper puts into order my last decade's work on the development of reading and dyslexia. It argues that the most general information processing deficit in developmental dyslexia lies in phonological processing and that studies of individual differences in reading development where intelligence is controlled generate patterns of associations which are essentially similar to those which arise from studies of developmental dyslexia. Developmental dyslexics are shown to resemble acquired surface dyslexics but they are even more similar to younger children of equivalent reading ability. We argue that a complete understanding of the development of reading can come only from longitudinal investigations of development itself. Such studies demonstrate typical sequences of interactive growth of related skills. They show how reading changes in nature as it is learned and that an early crux stage in its development is the adoption of an alphabetic reading strategy. We trace the precursors of the phonological knowledge that forms the foundations of grapheme-phoneme reading back through spelling, through explicit phonological awareness and, in turn, to its source in implicit phonological awareness. We confirm that the reading and spelling development of developmental dyslexics is limited by their prior failures to acquire this knowledge. 


\section{Reading Development, Dyslexia and Phonological Skills.}

\section{INTRODUCTION.}

I take this opportunity to review my last decade's work on the development of reading and dyslexia and to assess my current position. I will argue (1) the most general information processing deficit in developmental dyslexia lies in phonological processing, (2) studies of individual differences in reading development where intelligence is controlled generate patterns of associations which are essentially similar to those which arise from studies of developmental dyslexia, (3) developmental dyslexics resemble acquired surface dyslexics but are even more similar to younger children of equivalent reading ability, (4) an understanding of the development of reading can only come from longitudinal investigations of development itself, and such studies demonstrate typical sequences of interactive growth of related skills, (5) a key stage in the development of reading is the acquisition of an alphabetic strategy and we can trace the evolution of this skill from implicit phonological awareness through explicit phonological awareness to spelling and hence to reading itself.

\section{(1) PHONOLOGICAL PROCESSING IN DEVELOPMENTAL DYSLEXIA.}

When two letters of the same case are presented simultaneously and the child has to report whether they are the same $(\mathrm{OO})$ or different $(\mathrm{OB})$, dyslexic and control children do not differ either in the speed or in the accuracy with which they can perform this task. Nor are the dyslexic children or poor readers slower than age matched controls when the letters, though different, are visually confusable (OQ, RP, EF, CG) (Ellis, 1981a,b). It seems unlikely, therefore, that dyslexic children have difficulty in dealing with the visual characteristics of letters as such. In contrast, when two letters of different case have to be adjudged same $(\mathrm{Gg})$ or different $(\mathrm{Gw}, \mathrm{Gd})$ on the basis of name characteristics, the dyslexic 
children are reliably slower and more error prone than age-matched controls. It thus seems that dyslexic children have no extra difficulty in dealing with the visual aspects of letters as such, but that they show an impairment when the task demands the access and analysis of phonological features. This dissociation is similarly demonstrated in the study of Done and Miles (1978) who presented dyslexic subjects and age-matched controls with arrays of digits and afterwards made the correct digits available and asked the children to place them in the original order. At this task, where the stimuli were nameable, the dyslexic children scored considerably lower than the controls, but when non-verbal nonsense shapes were used as stimuli in place of digits the differences were minimal. Finally, when both groups had both been given Paired Associate Learning where names were learned for the nonsense shapes, the performance of the controls again became significantly superior.

This deficit in phonological access is confirmed in the wide range of demonstrations of dyslexic children being slow in naming letters, objects, colours, digits, pictures, non-words and words (Ellis and Miles, 1981) and their difficulties in verbal short-term memory which are often taken as symptomatic of the syndrome.

These findings underpin the modal view of developmental dyslexia as a deficiency in phonological processing: developmental dyslexics are specifically impaired on tasks requiring perception, access or analysis of phonological material and they evidence no dramatic disability to function with concrete or visual material (Ellis and Miles, 1981; Miles and Ellis, 1981; Frith, 1981; Vellutino, 1979; Spring and Capps, 1974)

\section{(2) STUDIES OF INDIVIDUAL DIFFERENCES IN READING DEVELOPMENT.}

In 1979 we recognised that the then-current knowledge of reading, reflected in reviews of thousands of individual studies of reading (e.g. Gibson and Levin, 1975, Vellutino, 1979, Vernon, 1971), predominantly arose from studies using ex post facto bivalent designs with little or no attempt to look for differential abilities. They had been performed by different 
investigators, with children of different cultures, education, age, socio-economic background and intelligence and they had involved radically different numbers of subjects. They had taken place over the last 50 years when educational practices had been changing. It was quite possible therefore that these reviews constituted a nomothetic generality which, from a heterogeneous population, reflects none of the individuals studied. Furthermore they potentially failed to lead to an understanding of the development of reading, since, if we want to study development we must do so directly. Only when the same persons are tested repeatedly over time does it become possible to identify developmental changes and processes of organisation within the individual. Cross-sectional studies which compare different groups of people at different stages of acquisition must always come a poor second when small but reliable changes with age are to be detected, where teaching methods and teachers change with time, and where we do not wish to make the false assumption that the abilities of a younger cross-section were necessarily present in the older cross-section at a previous time. They also fail us with regard to the determination of causality: a crosssectional study may show an association between two phenomena, but only a longitudinal investigation can determine which came first.

Therefore we embarked on a study of the first three years of reading development in the same children using a longitudinal differential design (Ellis and Large, 1987, 1988). The longitudinal nature of the study allowed a meaningful analysis of the changing nature of individual children's reading skill and the determination of which skills promote reading development and which benefit from it. The differential design allowed not only the determination of which skills are associated with reading, but also their relative importance.

A cohort of 40 children was assessed for their abilities on 44 variables which measured as wide a range of information-processing skills as was practically possible. Besides the full WISC there were a variety of measures of reading, spelling, vocabulary, STM, visual skills, auditory-visual integration ability, auditory/language abilities, language knowledge, and rote knowledge and ordering ability. The children were assessed on these measures each year, from 5 to 8 years old. In the first of our reports (Ellis and Large, 1987) we extracted three 
groups at age 8 on the basis of reading and IQ scores. Group A showed a specific reading disability (high IQ, low reading), Group B were good readers of similarly high IQ, Group C showed a more generalised reading deficit in that they were at the same level as Group A in reading but their IQ scores were low. The data was then searched retrospectively to describe the development of these patterns of ability from the very beginnings of reading acquisition.

The children with specific reading retardation differed from their better-reading peers in terms of the relatively few variables which concerned phonological segmentation, STM and naming. The children with generalised reading disability differed from their better-reading peers in almost every respect, but the strong discriminators concerned phonological processing. The children with specific reading disability differed from those with generalised reading disability in terms of intelligence and abilities which involve visual processing. These patterns of ability were broadly replicated at each age from 5 to 7 years old.

From the wide and varied test battery there were few tests which discriminated between these the children with specific reading disability and their age- and IQ-matched controls and they all concerned phonological processing, STM, or some aspects of accessing the articulatory equivalents of visual material. The most important discriminators were the rhyming tasks which require implicit use of phoneme segmentation and which had previously been demonstrated to be reliable discriminators between dyslexics and adequate readers in group studies (Snowling, Stackhouse and Rack, 1985), and to be reliable predictors of later reading difficulty (Bradley and Bryant, 1983). The next most strong discriminator was auditory digit span, a most common finding in the developmental dyslexia literature (see Ellis and Miles, 1981, Jorm, 1983 and Vellutino, 1979 for reviews). Next came other tests of STM for verbal material (auditory sentence span, auditory word span), and of phonological processing (sound blending, phoneme segmentation). We additionally found that the rate at which children can access the articulatory equivalents for colours discriminated between the groups, and we confirmed the typical WISC profile of dyslexic children where they had problems with the Digit Span, Comprehension, Information and Coding subtests (Spache, 1976). The only discriminator which was not of a phonological type was visual serial 
ordering which squeezed in at the bottom of the list, a suitable placement because of the dispute over whether visual encoding problems fall out of group studies as being associated with dyslexia: some affirm this to be the case (Benton, 1962, Ingram, 1971), some deny (Yule and Rutter, 1976, Ellis, 1981), some find it to be dependent on spatial frequency with the deficiency only in the transient subsystem (Lovegrove, Martin and Slaghuis, 1986), and some reinterpret the 'visual' tasks to involve implicit verbalisation strategies (Vellutino, 1979), but most would agree that such problems are negligible when compared with STM and phonological processing deficiencies.

None of the other tests, the larger part of the battery, significantly discriminated between these groups - the children with specific reading problems did not seem to show reliable patterns of problems of visual processing (on tests of visual closure, picture completion, letter search, coding, block design, object assembly or picture arrangement), nor syntactic skills, nor rote knowledge and ordering.

\section{(3) COMPARISONS BETWEEN THE DEVELOPMENTAL AND ACQUIRED}

\section{DYSLEXIAS.}

The term dyslexia is applied both to the difficulty a child may experience in learning to read and to reading problems resulting from brain damage in previously normal adults. Research on acquired dyslexia has recently undergone an intensive period of theoretical development and has led to a number of agreed categories of dyslexia, each having a characteristic pattern of reading errors, a different pattern of sensitivity to the characteristics of the material read, and a concomitant description in terms of deficit in information processing routes in models based on the analysis of normal adult reading (Patterson, 1981; Coltheart, Patterson and Marshall, 1980; Patterson, Marshall and Coltheart, 1985). For example, deep dyslexics have more difficulty reading orthographically regular non-words than real words, function words than content words and low imageability words than highly imageable words, but they are largely unaffected by word length or orthographic regularity. 
Surface dyslexics show the converse in that they are largely unaffected by lexicality, parts of speech or imageability, but are affected by word length and spelling regularity. Most current models of reading suggest that an isolated word may be read aloud by either of two routes. Those words that are in the reader's sight vocabulary may directly access both the word's phonological representation and its meaning. These will be read rapidly and accurately. In the case of words that are less familiar, reading is assumed to proceed via the application of either grapheme-to-phoneme translation rules, or analogies between groups of letters in the word being read and similar groups of letters in known words. Deep dyslexic patients are assumed to have the former direct route relatively less impaired than the grapheme-tophoneme or analogy based route. Surface dyslexics, on the other hand, are assumed to be capable of using the grapheme-to-phoneme route, but to be impaired in the operation of the whole word route; hence the use of their relatively automatic sight vocabulary is impaired but the ability to sound out words and non-words is relatively intact. When we compared developmental and acquired dyslexics (Baddeley, Ellis, Miles and Lewis, 1982; Baddeley, Logie and Ellis, 1988) we found that developmental dyslexics were more akin to surface dyslexics, with both groups being susceptible to the effects of spelling regularity, somewhat susceptible to word length effects, and insensitive to the content-function word distinction. On the other hand our developmental dyslexics were clearly highly susceptible to the lexicality effect, being much better at reading words than non-words, an effect which is not said to be prominent in the pattern of reading disability exhibited by surface dyslexics. The pattern of results for the developmental dyslexics was very similar to that of normal, younger children of an equivalent reading age.

Developmental dyslexics and young children resemble surface dyslexics in having a poorly developed sight vocabulary, and thus having to rely more extensively on the indirect rule-based route. They differ from them in that the adult acquired dyslexic has previously had a fully developed reading system and their grapheme-phoneme route is well developed, extensive and automatised. The developmental dyslexic's system has simply not yet 
developed and their phonological deficits slow and restrict their reading through this rulebased route, hence their exceptional difficulties with non-words.

Our understanding of developmental dyslexia is informed from comparisons with the acquired dyslexias, but it must also consider the way in which the reading process develops (Ellis and Large, 1987, 1988; Ellis, 1989; Marsh, Friedman, Welch and Desberg, 1981; Snowling, 1983; Frith, 1985) and it is to these matters that we now turn in order to understand the way in which phonological skills are brought to the reading process in development. It was first necessary to identify the overall patterns of the interactive development of the wide range of reading-related skills. Hence our first longitudinal study was broadly targeted and assessed many different abilities.

\section{(4) THE 'BROAD-BRUSH’ LONGITUDINAL STUDY}

We analysed our longitudinal highly-multivariate study (Ellis and Large, 1988) of the early reading development of forty children in several ways. At each year the patterns of associates of reading skill were determined (with and without control for IQ); the abilities at one point in time which were associated with later reading skill were charted for the whole group, for a subset of children who at 5 years old started with no reading skill, and for another group of children who were progressing rapidly at 7 years old; cross-lagged correlation comparisons were made to investigate causal paths. These analyses allowed us to broadly chart the course of reading development and the interactive ways in which associated skills such as spelling, reading, phonological awareness and syntactic knowledge grow from each other differentially at different stages of development.

These analyses demonstrated that the nature of reading skill changed rapidly in the first three years of acquisition. In information processing terms it began as an undifferentiated skill associated with knowledge of the letters of the alphabet, phonological awareness, and visual symbolic short-term memory processes. It then changed in character, being associated with holistic visual pattern recognition skills. By 6 years old phonological awareness and verbal short-term memory processes were by far the strongest associates. By 7 years old the 
better readers' skills were associated with analytic visual perceptual analysis, the learning of new symbol<>sound associations, and sound blending skill. Reading had become a multifaceted ability tapping a wide range of different skills - from language comprehension to analysis of the order of elements in a visual array - and different strategic blends of these abilities were now being used in different reading situations. The observed developmental sequence, which is similar to that described by Marsh et al. (1981) and Frith (1985) is detailed below:

Stage 1 of reading pertained to those children who could read no words at 5 years old and it was phonological awareness, letter recognition, and performance on visual digit span tasks which predicted their reading development over the next year. Stage 2 was predominantly visual with there being little evidence of involvement of grapheme-phoneme decoding. These first two stages of reading that derive from an analysis of associated skills map onto the first stage of reading that has been proposed from the analysis of children's early reading errors (Biemiller, 1970; Torrey, 1979; Weber, 1970). Marsh et al. (1981) call this the stage of linguistic substitution where the child uses a strategy of simple rote association between a simple unsynthesised visual stimulus and an unanalysed oral response. "The child typically centres on one aspect of the visual stimulus such as the first letter and associates that with the oral response ... Their natural strategy is congruent with the 'whole word' approach to teaching reading" (p201-202). Hence Frith (1985) calls this the logographic stage. If the child does not know the word she may guess on the basis of contextual cues. Marsh et al. suggest that the child next progresses to a stage of discrimination net substitution where "the number of graphemic features a young child can process is limited initially to the first letter, and it is only later that additional features such as word length, final letter etc. are added. The child at this stage appears to be operating according to a 'discrimination net' mechanism in which graphemic cues are processed only to the extent necessary to discriminate one printed word from another." (p203).

The associated skills which predicted reading development through Stages 1 and 2 here are exactly those which would allow this type of logographic reading. The letter recognition 
and visual digit span predictors of Stage 1 are consistent with the children concentrating on the analysis of the letters in words. The visual predictors of Stage 2 suggest that the child in this stage was using a strategy of remembering the visual features of the words they could read.

Stage 3 was very different in that this next style of reading, whilst capitalising on development so far, became much more concerned with phonological awareness, soundsymbol transcoding, and auditory-verbal STM. Again this stage parallels that proposed from the analysis of children's reading errors. Marsh et al. call their next stage that of Sequential Decoding, Frith terms it Alphabetic. In both of these models this next stage is characterized by the use of individual graphemes and phonemes and their correspondences. "It is an analytic skill involving a systematic approach, namely decoding grapheme by grapheme. Letter order and phonological factors play a crucial role. This strategy enables the reader to pronounce novel and nonsense words" (Frith, 1985, p308). As with the previous stages we see from our analysis of the reading-associated skills that the shift to Stage 3 capitalised on those already present skills which enable this reading strategy. But also evident was the true interactive nature of reading development: the phonological awareness and auditory-verbal STM which Stage 3 built upon were to a large degree themselves growing from Stage 2 reading (Ellis and Large, 1988; Ellis, 1988, 1989).

In Stage 4 the set of grapheme-phoneme correspondence rules became much more extensive and the ease with which children learned these new associations determined their progress in reading. Analytic visual perceptual skills also became associated. Marsh et al. characterize their next stage of reading as being an extension to the simple decoding strategy (which was based on one-to-one correspondence) where the child now learns more complex rules of orthographic structure - the units are letter groups and higher order conditional rules (like the magic $e$ rule) are used. Our findings of sound-symbol learning and visual analysis skills being associated with reading at this stage are certainly consistent with this characterisation. Frith, however, suggests that the next stage of reading involves orthographic strategies where the words are instantly analysed into orthographic units 
without phonological conversion. "The orthographic units ideally coincide with morphemes. They are internally represented as abstract letter-by-letter strings. These units make up a limited set that - in loose analogy to a syllabary - can be used to create by recombination an almost unlimited number of words." (Frith, 1985, p308). Both the models of Frith and Marsh et al. emphasize analysis of multiple letter orthographic units, but Frith is implying that practice at the analysis of orthographic sequences will eventually allow non-phonological whole-morpheme direct lexical access, with post-lexical phonological retrieval. The patterns of associations found in our study appear to reflect the superior reader's entry into this final stage. Finally we also observed an increasing use of grammatical and schematic linguistic knowledge through Stages 3 and 4.

This first longitudinal study allowed us to chart the interactions between different skills in the first three year's development of reading, to identify the very different types of reading at different stages of development, and to clarify the prior skills which promoted reading development and the skills which themselves grow from practice in reading. We identified some powerful reciprocal interactions in development, for example those between reading and STM where we found from the pre-reading analyses that phonological skills promoted the acquisition of letter knowledge and that these two abilities, together with visual STM, led the development of reading and yet, from the post-reading analyses, reading promoted the acquisition of phonological skills and Auditory STM, and that the phonological skills in turn led to the development of visual STM (Ellis, 1989)! The literature on this topic thus far had tended to ask which direction of causality applies (eg Ehri, 1979; Bradley and Bryant, 1983; Bryant and Bradley, 1985; Bryant and Goswami, 1987). The answer is that both directions apply because a new skill invariably initially builds on whatever relevant abilities are already present, then, as it is used, it may well legitimatize and make more relevant (Istomina, 1975) those prior skills and so in turn cause their further development. Stanovich has persuasively argued the case for reciprocal relationships and bootstrapping effects: "In short, many things that facilitate further growth in reading comprehension ability - general knowledge, vocabulary, syntactic knowledge - are developed by reading itself”' (Stanovich, 1986, p364), 
"interrelationships between the various subskills of reading and intelligence increase with age, probably due to mutual facilitation" (Stanovich, Cunningham and Feeman, 1984, p 278, my emphasis). In the evolution of our research we have used three metaphors for skill development: river and delta formation (see Hardy, 1965), pace-makers and followers, and symbiosis. They are all images of reciprocal interactions of elements over time. Such is the growth and development of skill.

This study also provided details about the move from early whole-word reading to a strategy which capitalises on grapheme-phoneme associations. We have shown in sections 1 , 2 and 3 that developmental dyslexics are particularly deficient in their phonological abilities, the very skills which are needed for learning these grapheme-phoneme associations. Therefore a finer-grained longitudinal study was needed to identify how phonological skills grow and become incorporated into the reading process.

\section{(5) THE 'FINER-GRAINED' LONGITUDINAL STUDY}

Although the importance of phonological awareness (PA) in the acquisition of reading had been established, causal pathways between the two abilities eluded clear definition (Bryant and Goswami, 1987; Shanahan and Lomax, 1986) since there are many and various factors which might influence studies of the co-development of phonological awareness and reading, viz., (i) the range of phonological awareness skills tapped by different tasks (Lewkowicz, 1980; Ellis and Large, 1988; Stanovich, Cunningham and Cramer 1984), (ii) the range of different types of reading tapped by different reading tasks and the child's ability to relate sound to graphic information (Lomax and McGee, 1987), (iii) short term and working memory (Ellis, 1988), and (iv) different methods of reading instruction ( Morais, Cary, Alegria and Bertelson, 1979; Alegria, Pignot and Morais 1982). Research that examines the relationship of phonological awareness to the emergence of literacy had often neglected spelling as a bona fide agent that independently influences and is influenced by phonological awareness and reading. Whilst it had been acknowledged that use of a 
phonological strategy plays a fundamental role in spelling before it becomes important in reading (Smith, 1973; Bryant and Bradley, 1980; Frith, 1980; Snowling and Perin, 1983; Juel, Griffith and Gough 1986), comparatively little attention had been focused on the possible routes of interaction among reading, spelling and phonological skills. Correlational studies provided evidence of a strong relationship between early reading and spelling and between spelling and phoneme awareness (Snowling and Perin, 1983; Juel, Griffith and Gough 1986; Ellis and Large, 1987). However, the form of causal connections could not be determined from correlations alone.

Theoretical analyses which assign spelling a major role in the development of phonological as well as reading skills include Chomsky (1977), Elkonin (1973), Lewkowicz (1980) and Ehri and Wilce (1987). In a three-phase model of reading acquisition Frith (1985) proposes that an alphabetic or sound strategy is first utilized in spelling practice and later carried over to reading, which the child has previously approached using a logographic or visual strategy. Yet only a few studies have been designed to explore the manner in which spelling contributes to or benefits from phonological and reading skills, although Ehri and Wilce (1987) have recently demonstrated transfer of phonological strategy from spelling to reading.

We needed a broader and more detailed description of the interactive development of all three components: reading, spelling and phonological awareness. Cataldo and Ellis (1988, 1989) therefore adopted a longitudinal design to identify the early sequences of interactive development in reading, spelling and phonological awareness skills. We elucidate the early causal relations among these three variables by following the development of each skill in a group of children as they move from preliteracy through the beginning stages of learning to read and spell.

In this study the early interactive development of reading, spelling and phonological awareness are charted in a group of 28 children during their first three years in school. During this time the children were tested at four intervals in reading and spelling real and 
nonsense words, phoneme segmentation and auditory categorization. The Wechsler Preschool Primary Scale of Intelligence was included in the set of initial assessments. A test of phoneme segmentation was given as a measure of explicit phonemic awareness and a test of auditory categorization was taken as a measure of implicit phonological awareness. The majority of the sample had only begun to attend school when the initial assessments were taken at the beginning of the school year when their mean age was 4 years 6 months. The children were retested at the end of their first school year, at the beginning of the second year and finally at the beginning of the third school year. Exploratory (LISREL) causal path analyses were used to investigate the contribution of each ability to the subsequent growth of skill in word recognition, spelling and phonological awareness. The patterns of interaction among these three abilities provided a preliminary framework for mapping the early stages in the acquisition of literacy.

By broadening the phonological awareness-reading paradigm to include spelling, we were able to see a clearer picture of the early interaction among these abilities. There were three measured phrases of development. Phase One spans the children's first year in school. Phase Two charts the development from spring of the first school year to autumn of the second year. Phase Three looks at development from the beginning of the second year in school to the beginning of the third year. The Phase One pathweights from spelling to reading real words and nonsense words identify spelling as an important contributor to the early formation of reading. This pattern of influence is repeated much more strongly in the second phase with high pathweights from spelling to reading real words and nonsense words. The pronounced influence of spelling on reading contrasts with a negligible contribution of reading to spelling in both Phases 1 and 2. Implicit PA initially predicts early attempts to read as well as to spell but looses its influence on both reading and spelling in the following two phases. In contrast to the diminishing predictive power of implicit PA, explicit PA consistently predicts spelling in all three phases, this influence increasing with phase. Explicit PA only emerges as a strong predictor of reading in Phase Three. 
The early transfer between reading and spelling appears to be unidirectional: knowledge gleaned from spelling is contributing to reading. Similarly, both implicit and explicit PA affect spelling development with explicit PA increasing its influence as the contribution of implicit PA diminishes. Later in the developmental sequence, explicit PA begins to contribute directly to reading. The pattern of interactions among abilities in Phase One clarifies the different roles of implicit and explicit PA in the early formation of reading skill. Implicit information about the sound properties of words directly affects early reading attempts: explicit knowledge of phonemic content influences reading via spelling experience. Beginners may be be using implicit PA both to help them detect acoustic properties that define a word by its sound boundaries and to detect sounds with salient qualities, and their use of these rudimentary sound strategies allows them to form associations between sounds in spoken words and pronunciations and to call upon these associations to perform phoneticcue reading (Ehri and Wilce, 1985). The use of implicit awareness of rhyming components in words may also help beginners to generalize from an unknown word to a word that contains a similar spelling (Bryant and Goswami, 1987), but this strategy is more likely to be employed at later stages of reading development when children have enough lexical entries from which to generalize. The first evidence of the direct influence of explicit PA on reading occurs in Phase Three, when explicit PA predicts ability to read nonwords. In earlier phases explicit PA does not influence reading directly but acts as the strongest predictor of spelling both real and nonsense words. In turn, spelling is the most consistent predictor of reading.

This early interactive sequence describes the pattern of growth from pre-alphabetic to alphabetic stage reading (Frith, 1985). While implicit knowledge of the sound properties of words helps children forge initial connections between the printed word and its pronunciation, spelling acts as a mediator for the use of explicit PA until the child begins alphabetic stage reading by directly applying explicit PA to reading. Our data suggest that as children practise spelling they develop proficiency in the use of the alphabetic principle and apply this knowledge to the task of reading. The emergence of explicit PA as a significant predictor of reading marks the entry into the alphabetic stage of reading. This interpretation 
accords with children's introduction to reading during the first few years in school. They learn to rely on contextual clues and accompanying pictorial information in conjunction with distinctive graphic features in the printed word in order to arrive at a meaningful rendition of text. With increased reading experience, this early reading strategy is expanded to include reliance on partial phonetic cues accessed through constituent letters and on similarity of the component letters of the to-be-read-string to component letters of real words stored in the lexicon. In this way novice readers evolve a prealphabetic strategy that they associate with the quickest route to reading real words for meaning. But when children are confronted with nonsense or new words in the absence of meaningful context and analogous counterparts in the real word lexicon, they may switch to an alphabetic approach. Here we see evidence of the selective use of strategies for different purposes. Children are able to shift from one level of reading strategy to another, depending on the demands of the task. Beginners attempt to read unknown words via a strategy of combining context, visual and phonetic cues, and only when this fails, switch to deciphering. Initially, deciphering is used exclusively for reading unknown words when other strategies fail, but with practice children integrate this alphabetic approach into their repertoire set of strategies and eventually the beginner comes to appreciate the general usefulness of this deciphering strategy, perhaps temporarily reneguing other approaches to word recognition for the sake of practising this skill and gaining automaticity.

Models of reading and spelling must describe development, the movement from one stage to the next. Our results describe the ways in which spelling acts as a mediator for the influence of explicit phonological awareness on reading. Children's very first efforts at reading are characterized by a visual or logographic strategy where letters are analyzed for salient graphic cues to rapid word recognition; this is the PreAlphabetic Stage. When a small number of pronunciations can be accessed in this manner, the child may embark upon a more advanced strategy of using associations between partial phonetic cues in the spoken word with letters in the printed version and subsequently utilize these associations to recognize the words. Children appear to use implicit PA to help them make these rudimentary sound 
analyses of pronunciation. In addition, spelling practice may contribute to the store of associations between the spoken words and letter-sound constituents in printed words. At first, spelling may encourage children to focus on the first letter of printed words and to begin to analyse this first letter, in the reading task, for phonetic cues to pronunciations. Thus, the practice of turning attention to the first letter-sound unit in spelling may influence children to discriminate between stored pronunciations on the basis of the first letter of the printed word, the 'discrimination net substitution' of Marsh et al. (1981). As visual and phonetic cue strategies make increasing demands on the child's memory, the efficiency of this strategy decreases. Conversely, as the source of knowledge about letter-sound associates, and the relationships between letters in printed words and sounds in spoken words swells, the child is discovering that s/he can rely on the use of this knowledge for successful word recognition. Our studies support the idea that the transition from pre-alphabetic stage reading to alphabetic stage reading is facilitated by spelling. By employing explicit PA in spelling practice, the child gains familiarity with the alphabetic nature of writing and builds a reliable fund of information about letter-sound correspondences and explicit phonemic content in words. Spelling affords the opportunity to forge a meaningful link between phonological awareness and letter-sound knowledge. This connection is a prerequisite to the development of phonological strategies in reading.

\section{CONCLUSIONS}

These studies have confirmed the phonological deficits in developmental dyslexia. They show how reading changes in nature as it is learned and that an important early stage in its development is the adoption of an alphabetic reading strategy. We trace the precursors of the phonological knowledge that forms the foundations of grapheme-phoneme reading back through spelling, through explicit phonological awareness and in turn to its source in implicit phonological awareness. We confirm that the reading and spelling development of developmental dyslexics is limited by their prior failures to acquire this knowledge, as Frith (1985, p324) says: "Classic developmental dyslexia is the failure of alphabetic skills". We discuss the educational implications of these findings in Ellis \& Cataldo (1989). 
There remains the need for further longitudinal studies which go back even further into early development. One promising example is that of MacLean, Bryant and Bradley (1987) who demonstrate the role of children's early experience of nursery rhymes in their gaining initial implicit phonological awareness. The question that then arises is why, assuming developmental dyslexics receive equal such early exposure, they do not assimilate this knowledge. Another is that of Gathercole and Baddeley (1989) who demonstrate even more pervasive effects of deficient phonological short-term memory whereby even the learning of new vocabulary is retarded. And then we must determine the neurological and genetic reasons which underlie this constitutional disability. 


\section{ACKNOWLEDGEMENTS}

I express grateful thanks to my co-workers, Alan Baddeley, Gordon Brown, Suzanne Cataldo, Barbara Large, Tim and Elaine Miles. 


\section{REFERENCES}

Alegria, J., Pignot, E. and Morais, J. (1982) Phonetic analysis of speech and memory codes in beginning readers. Memory and Cognition, 10, 451-456.

Baddeley, A.D., Ellis, N.C., Miles, T.R. and Lewis, V. (1982) 'Developmental and Acquired Dyslexia: A Comparison'. Cognition,11, 185-199.

Baddeley, A.D., Logie, R.H. and Ellis, N.C. (1988) 'Characteristics of Developmental Dyslexia'. Cognition, 29, 197-228.

Benton, A. L. (1962) Dyslexia in relation to form perception and directional sense. In Money, J. (Ed.) Reading Disability. Baltimore: John Hopkins Press.

Biemiller, A. (1970) The development of the use of graphic and contextual information as children learn to read. Reading Research Quarterly, 6, 75-96.

Bradley ,L. and Bryant, P. E. (1983) Categorizing sounds and learning to read - a causal connection. Nature, 301, 419-421.

Bryant, P.E. and Bradley, L. (1985) Children's Reading Problems. Oxford, Blackwell.

Bryant, L. and Goswami, U. (1987) Phonological awareness and learning to read. In J. R. Beech and A.M. Coley (Eds.) Cognitive Approaches to Reading. Chichester: Wiley.

Cataldo, S. and Ellis, N.C. (1988) "Spelling, Reading and Phonological skills in interactive development". Journal of Research in Reading, 11 (2), 86-109.

Cataldo, S. and Ellis, N.C. (In Press, 1989) "Learning to Spell, Learning to Read". To appear in P.D. Pumphrey and C.D. Elliott (Eds.) Children's Difficulties in Reading, Writing and Spelling: Challenges and Responses. Baisingstoke: Falmer Press.

Chomsky, C. (1977) Approaching reading through invented spelling. In L.B. Resnick and P.A. Weaver (Eds.) The Theory and Practice of Early Reading. Vol. 2. Hillsdale, N.J.: Erlbaum.

Coltheart, M, Patterson, K. and Marshall, J.C. (Eds.) Deep Dyslexia. London: Routledge and Kegan Paul. 
Done, D.J. and Miles, T.R. (1978) 'Learning, memory and dyslexia'. In M.M. Gruneberg, P.E. Morris and R.N. Sykes (Eds.) Practical Aspects of Memory. London: Academic Press.

Ehri, L.C. (1979) Linguistic insights: Threshold of reading acquisition. In T.G. Waller and G.E. MacKinnon (Eds.) Reading Research: Advances in Theory and Practice. Vol. 1. New York: Academic Press.

Ehri, L.C. and Wilce, L.S. (1985) Movement into reading: is the first stage of printed word learning visual or phonetic? Reading Research Quarterly, 20, 163-179.

Ehri, L.C. and Wilce, L.S. (1987) Does learning to spell help beginners learn to read words? Reading Research Quarterly, 22, 47-65.

Elkonin, D.B. (1973) U.S.S.R. In J. Downing (Ed.) Comparative Reading. New York: Macmillan.

Ellis, N.C. (1981a) 'Information processing views of developmental dyslexia I-IV'. Dyslexia Review,4 (1), 10-21 and 4 (2), 5-17.

Ellis, N.C. (1981b) 'Visual and name coding in dyslexic children'. Psychological Research,43, 201-218.

Ellis, N.C. (1988) 'The development of literacy and short-term memory.' In M.M. Gruneberg, P.E. Morris and R.N. Sykes (Eds.) Practical Aspects of Memory: Current Research and Issues Volume 2: Clinical and Educational Implications. Chichester: Wiley.

Ellis, N.C. (In Press, 1989) "Reading, Phonological Processing and STM: Interactive Tributaries of Development" To appear in Journal of Research in Reading

Ellis, N.C. and Cataldo, S. (Under submission, 1989) The role of spelling in learning to read. Ellis, N.C. and Large, B. (1987) 'The development of reading: as you seek so shall you find.' British Journal of Psychology, 78, 1-28.

Ellis, N.C. and Large, B. (1988) 'The Early Stages of Reading: A longitudinal study.' Applied Cognitive Psychology, 2 . 47-76.

Ellis, N.C. and Miles, T.R. (1981) 'A lexical encoding deficiency I: experimental evidence'. In G. Th. Pavlidis and T.R. Miles (eds.) Dyslexia Research and Its Applications to Education. Chichester: Wiley. 
Frith, U. (1981) 'Experimental approaches to developmental dyslexia: an introduction.' Psychological Research,43, 97-110.

Frith, U. (1985) Beneath the surface of developmental dyslexia. In Patterson, K., Coltheart, M. and Marshall, J. (Eds.) Surface Dyslexia. London: Erlbaum.

Gathercole, S.E. and Baddeley, A.D. (1989) Evaluation of the role of phonological STM in the development of vocabulary in children. Journal of Memory and Language, 28, 200213.

Gibson, E. and Levin, H. (1975) The Psychology of Reading. Cambridge Mass.: MIT Press. Hardy, A. (1965) The Living Stream. London: Collins.

Ingram, T. T. S. (1971) Specific learning difficulties in childhood: a medical point of view. British Journal of Educational Psychology, 41, 1, 6-13.

Istomina, Z.M. (1975) The development of involuntary memory in preschool age children. Soviet Psychology, 13, 5-64.

Jorm, A. F. (1983) Specific reading retardation and working memory: a review. British Journal of Psychology, 74, 311-342.

Juel, C., Griffith, P.L. and Gough, P.B. (1986) The acquisition of literacy: a longitudinal study of children in first and second grade. Journal of Educational Psychology, 78, 243255.

Lewkowicz, N.K. (1980) Phonemic awareness training: what it is and how to teach it. Journal of Educational Psychology, 72, 686-700.

Lomax, R.G. and McGee, L.M. (1987) Young children's concepts about print and reading: toward a model of word reading acquisition. Reading Research Quarterly, 22, 237-256. Lovegrove, W. , Martin, F. and Slaghuis, W. (1986) A theoretical and experimental case for a visual deficit in specific reading disability. Cognitive Neuropsychology, 3, 225-267.

MacLean, M., Bryant, P. and Bradley, L. (1987) Rhymes, nursery rhymes and reading in early childhood. Merrill-Palmer Quarterly, 33, 255-281.

Marsh, G., Friedman, M.P., Welch, V. and Desberg, P. (1981) A cognitive-developmental theory of reading acquisition. In Waller, T.G. and Mackinnon, G.E. (Eds.) Reading Research: Advances in Theory and Practice. Vol. 3. New York: Academic Press. 
Miles, T.R. and Ellis, N.C. (1981) 'A lexical encoding deficiency II: clinical observations'. In G.Th. Pavlidis and T.R. Miles (eds.) Dyslexia Research and Its Applications to Education. Chichester: Wiley.

Morias, J., Cary, I.L., Alegria, J. and Bertelson, P. (1979) Does awareness of speech as a sequence of phones arise spontaneously? Cognition, 7, 323-331.

Patterson, K. (1981) Neuropsychological approaches to the study of reading. British Journal of Psychology, 72, 151-174.

Patterson, K.E., Marshall, J.C. and Coltheart, M. (Eds.) Surface Dyslexia. London: Erlbaum. Shanahan, T. and Lomax, R. G. (1986) An analysis and comparison of theoretical models of the reading-writing relationship. Journal of Educational Psychology, 78, 116-123.

Smith, F. (1973) Alphabetic writing - a language compromise? In F. Smith (Ed.) Psycholinguistics and Reading. New York: Holt Rinehart and Winston.

Snowling, M. (1983) The comparison of acquired and developmental disorders of reading A discussion. Cognition, 14, 105-118.

Snowling, M. and Perin, D. (1983) The development of phoneme segmentation skills in young children. In J. Sloboda (Ed.) The Acquisition of Symbolic Skills. London: Plenum Press.

Snowling, M. J., Stackhouse, J., and Rack, J. (1985) Phonological dyslexia and dysgraphia: developmental aspects. Cognitive Neuropsychology, 3, 309-339.

Spache, G. D. (1976) Investigating the Issues of Reading Disabilities. Boston: Allyn and Bacon.

Spring, C. and Capps, C. (1974) Encoding speed, rehearsal and probed recall of dyslexic boys. Journal of Educational Psychology, 66, 780-786.

Stanovich, K.E. (1986) Matthew effects in reading: Some consequences of individual differences in the acquisition of literacy. Reading Research Quarterly, XXI, 360-407.

Stanovich, K.E., Cunningham, A.E. and Feeman, D. J. (1984) Intelligence, cognitive skills, and early reading progress. Reading Research Quarterly, XIX, 278-303. 
Torrey, J.W. (1979) Reading that comes naturally: the early reader. In Waller, T.G. and MacKinnon, G.E. (Eds.) Reading Research: Advances in Theory and Practice. Vol. 1. New York: Academic Press.

Vellutino, F. R. (1979) Dyslexia: Theory and Research. Cambridge, Mass.: M.I.T. Press. Vernon, M.D. (1971) Reading and its Difficulties. Cambridge: Cambridge University Press.

Weber, R.M. (1970) A linguistic analysis of first-grade reading errors. Reading Research Quarterly, 5, 427-451.

Yule, W. and Rutter, M. (1976) Epidemiology and social implications of specific reading retardation. In Knight, R. M. and Bakker, D. J. (Eds.) The Neuropsychology of Learning Disorders. Baltimore: University Park Press. 